\title{
Nonsternotomy multivessel coronary artery bypass grafting: A key development in cardiac surgery
}

\author{
Marc Ruel, MD, MPH, FRCSC, FCCS, FAHA
}

\section{A NEED FOR LESS-INVASIVE CORONARY BYPASS SURGERY}

In the 1990s and early 2000s, attempts at performing lessinvasive coronary artery bypass grafting $(\mathrm{CABG})$ were largely restricted to the minimally invasive direct coronary artery bypass operation, itself a variation of the first CABG operation performed-in 1964 and through a thoracotomy - by Kolesov and Potashov. ${ }^{1}$ With the exception of multiple anterior target coronary vessels and other rare favorable combinations, multivessel bypass grafting through a nonsternotomy incision was not considered feasible until a large consecutive patient series was published in $2009 .^{2}$ These minimally invasive (MICS) CABG data became a catalyst for the adoption, over the ensuing decade, of this operation at other expert centers in America, Asia, Europe, and Oceania. Nowadays, it is estimated that thousands of MICS CABGs are performed every year. Nevertheless, multivessel MICS CABG remains a technically challenging operation performed only at select centers. Complete ease of the surgeon and team at off-pump coronary artery bypass $(\mathrm{OPCAB})$ represents 1 prerequisite, after which surgeons should initiate single-vessel MICS CABG to the left anterior descending artery, performed either conventionally or with robotic assistance. Numerous training programs and peer-to-peer options exist for surgeons and teams who wish to learn and develop MICS CABG. The outcomes of this operation have also been validated by several groups, and data pertaining to its safety, feasibility, adoptability, angiographic patency of grafts and, as of recently, long-term durability, are now available. ${ }^{3-6}$ A randomized clinical trial comparing multivessel surgical revascularization by MICS CABG versus regular

\footnotetext{
From the Division of Cardiac Surgery, University of Ottawa Heart Institute, Ottawa, Ontario, Canada.

The Minimally Invasive Cardiac Surgery Program is supported in part by the Crabtree Foundation (https://www.crabtreefoundation.com) and by an Endowed Research Chair in Cardiac Surgery.

Received for publication Aug 2, 2021; accepted for publication Sept 16, 2021; available ahead of print Sept 22, 2021.

Address for reprints: Marc Ruel, MD, MPH, FRCSC, FCCS, FAHA, University of Ottawa Heart Institute, 3402-40 Ruskin St, Ottawa, Ontario, K1Y 4W7, Canada (E-mail: mruel@ottawaheart.ca).

JTCVS Techniques 2021;10:162-7

2666-2507

Copyright (C) 2021 The Author(s). Published by Elsevier Inc. on behalf of The American Association for Thoracic Surgery. This is an open access article under the CC BY-NC-ND license (http://creativecommons.org/licenses/by-nc-nd/4.0/).

https://doi.org/10.1016/j.xjtc.2021.09.033
}

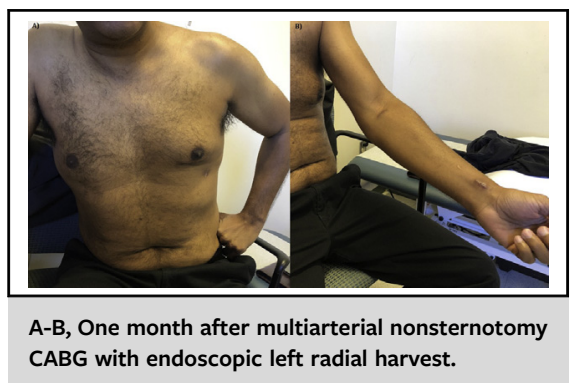

CENTRAL MESSAGE

The CABG operation of the

future must be safe, effective, and durable while less invasive

and widely applicable. Nonsternotomy multivessel CABG is an important step in that direction.

See Commentary on page 168.

sternotomy has, as of this writing, completed nearly one half of its recruitment.

Because a sternotomy incision can lead to healing issues or chronic pain in nearly $30 \%$ of patients, with the average time period needed to recover from CABG approaching 1 year, ${ }^{8-12}$ it is imperative that our specialty evolves by endorsing safe, validated ways to provide the therapeutic robustness of surgical coronary revascularization while avoiding the intrusiveness of a sternotomy. In this article, salient technical points about the performance of multivessel MICS CABG and key remaining questions related to its degree of adoption by the cardiac surgical community are presented.

\section{HOW MICS CABG IS PERFORMED: A \\ STEP-BY-STEP APPROACH \\ Inclusion and Exclusion Criteria \\ Inclusion and exclusion criteria are outlined in Table 1.}

\section{Positioning and Incising}

In the operating room, the anesthetized patient is placed in a 20 to $30^{\circ}$ right decubitus position, and the left lung is isolated and unventilated (Figure 1). The chest is entered in the fourth or fifth intercostal space, depending on the anticipated position of the coronary targets, with several 
TABLE 1. Inclusion and exclusion criteria for multivessel MICS CABG

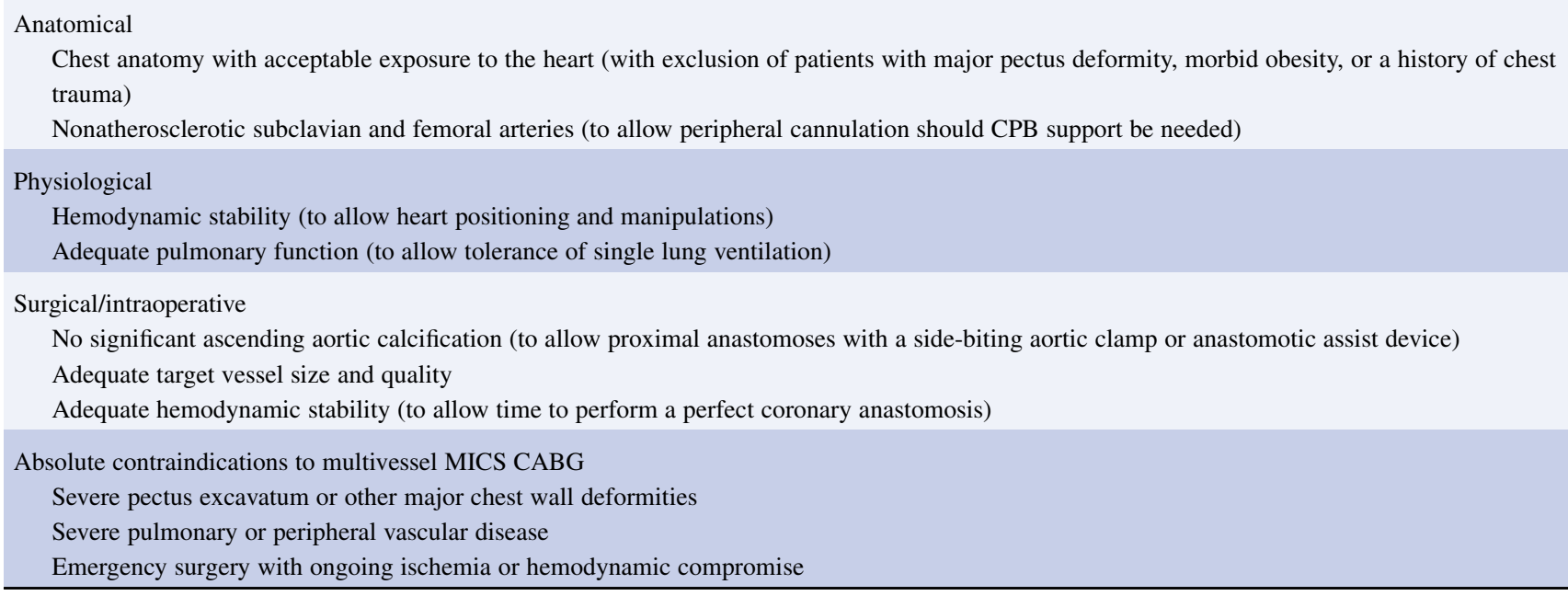

$C P B$, Cardiopulmonary bypass; $M I C S C A B G$, minimally invasive coronary artery bypass grafting.

centers using preoperative computed tomography planning for this purpose. For most patients undergoing multivessel MICS CABG, the 4- to 5-cm thoracotomy is centered on the midclavicular/nipple line and enters the pleural space one intercostal space cephalad to the apex of the heart, which can be estimated by triangulating the incision site between the sternal angle and xyphoid process (with the left arm elevated) and confirming, upon chest entry, by digital cardiac palpation. If the wrong intercostal space is entered, the surgeon can easily move by one space caudal or cephalad through the same skin/pectoralis incision. Alternatively, a robotic-assisted approach to incise the pericardium and harvest one or both internal thoracic arteries (ITAs) can be used.

\section{Conduit Harvesting}

A left radial artery conduit may be harvested before positioning the patient and ideally should be carried out endoscopically. The left ITA is exposed by pulling the thoracotomy retractor, comprising an upper chest wall lift blade, upward and toward the patient's left side with a pulley (Figure 2). The left ITA is harvested over its entire length, from the caudal end of the incision to the subclavian vein cephalad. The right ITA

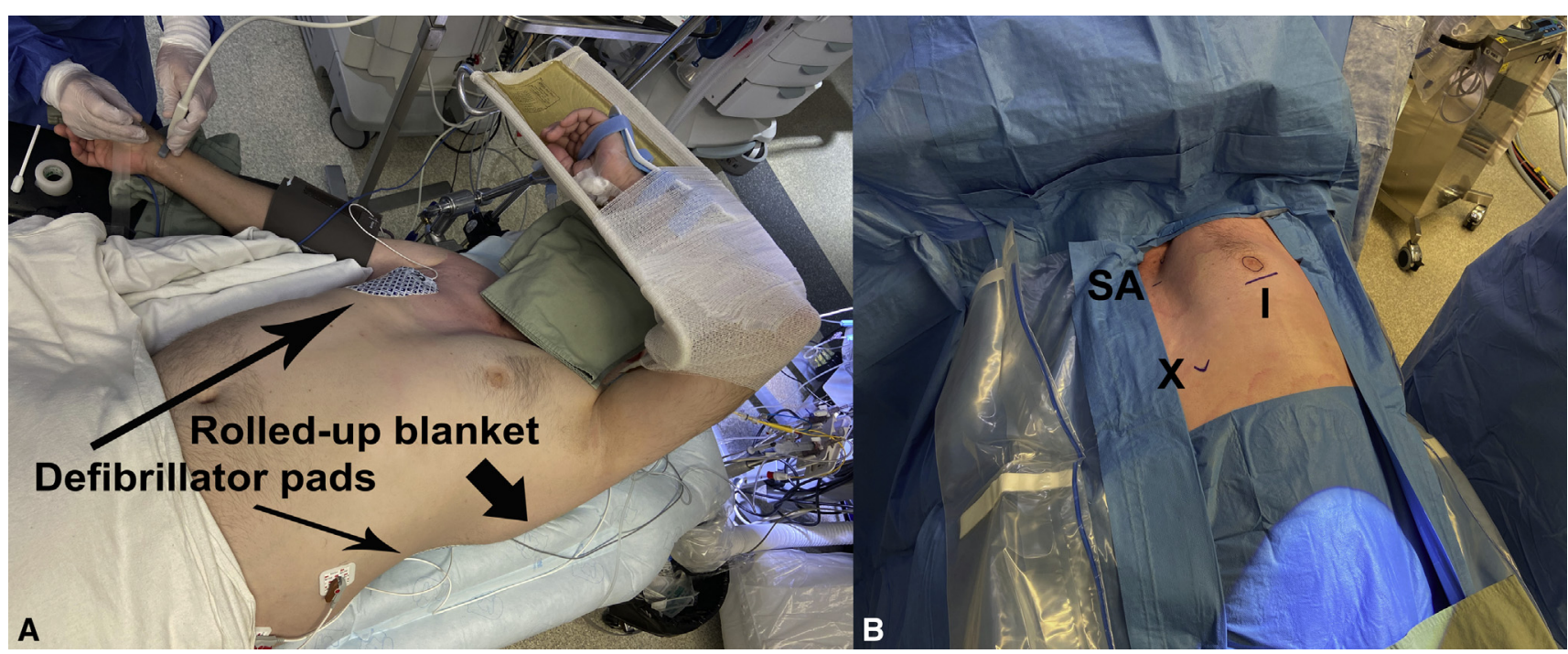

FIGURE 1. Positioning for MICS CABG. A, Left panel: The patient is positioned in a right decubitus position, with back and shoulder support over a patient warmer, and with the left arm elevated and placed over gel padding. The right arm-if not previously catheterized-can be used for concomitant right radial artery harvest; more typically, the left radial artery is harvested prior to positioning. B, Right panel: With the left arm elevated, a 5-cm thoracotomy incision $(I)$ is performed just caudal to the left nipple, as determined by triangulation between the sternal angle $(S A)$ and the xiphoid process $(X)$. This simple approach leads to the correct intercostal space for most MICS CABG cases. Consent to the use of the photos was provided by the patient. 


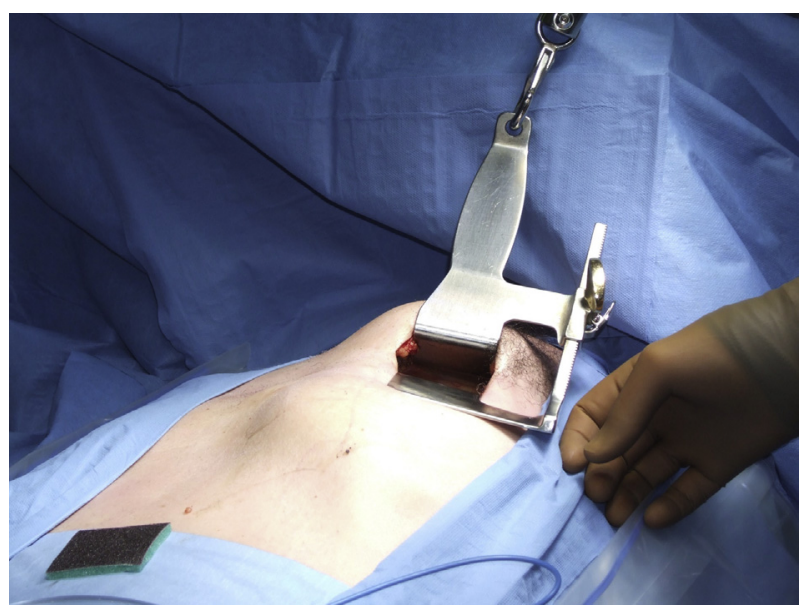

FIGURE 2. MICS CABG incision and harvest of the left internal thoracic artery. A pulley retracts, from a left cephalad position, a small thoracotomy retractor fitted with a long blade. This progressively exposes the full length of the left internal thoracic artery within the closed chest.

can also readily be harvested, in lean patients, by using an additional subxiphoid lift retractor. ${ }^{13,14}$ Saphenous vein conduits are harvested concomitantly to ITA takedown.

\section{Proximal Flow Sourcing}

Two approaches can be used: independent grafts with aortic proximal anastomoses or composite left ITA-based Y-grafting. Excellent results have been achieved with either method. With regard to handsewn proximal aortic anastomoses, the technique has been well described. ${ }^{15}$ It involves pulling the thoracotomy retractor from the patient's right cephalad aspect; keeping the right ventricle filled at a safe minimum; incising the pericardium up to its reflection anterior to the ascending aorta; using multiple pericardial stay sutures to mobilize the pericardium caudally towards the left thoracotomy; placing a gauze anterior to the superior vena cava on the right lateral aspect of the ascending aorta; retracting the right ventricular outflow tract caudally and toward the left with an epicardial stabilizer inserted 2 intercostal spaces caudal to the small thoracotomy; side clamping the ascending aorta using a Kay-Lambert clamp with a systolic blood pressure of 75 to $85 \mathrm{~mm} \mathrm{Hg}$; and performing handsewn anastomoses under direct vision (Figure 3), with a high likelihood that a knot pusher will be required to tie the polypropylene sutures.

For a Y-graft based strategy, which provides the advantages of an anaortic configuration, several methods can be achieved within the closed chest. Important technical aspects include to source the composite graft as proximally as feasible on the left ITA, and stabilize the anastomosis site inside the chest away from the beating heart during

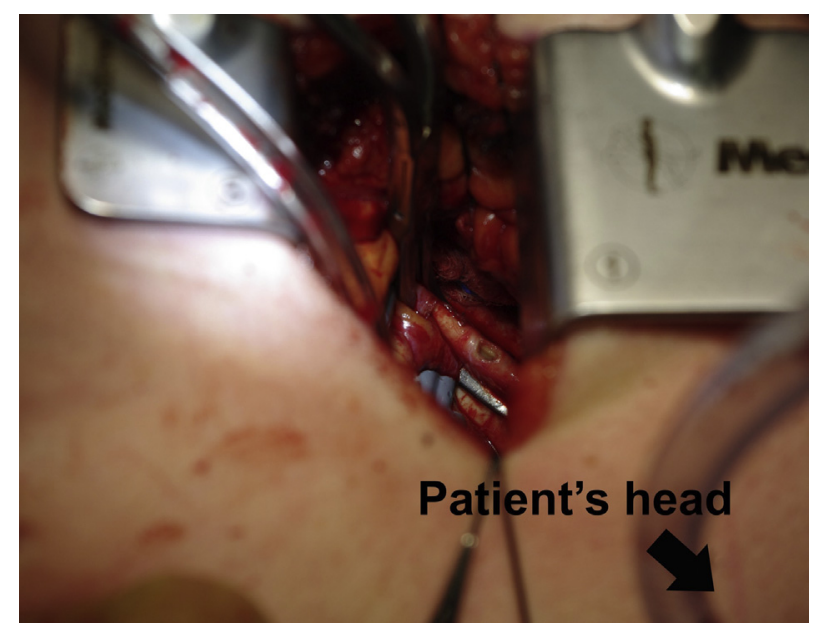

FIGURE 3. MICS CABG proximal anastomoses. Through a 5-cm thoracotomy incision, the ascending aorta can readily be exposed for handsewn proximal anastomoses, using tangential aortic clamping.

Y-graft construction, by resting the conduits on the epicardial stabilizer, covered with a cut sterile glove. ${ }^{14}$

\section{Distal Anastomoses}

A suction-type cardiac positioner (often misnamed "apical" positioner)—such as one used for regular OPCAB but removed from its shaft and with an umbilical tape tied around it above its suction cup-is used to expose the inferior and lateral wall vessels. If possible, the left ITAleft anterior descending graft is performed last to avoid risking damaging it during other manipulations. Inferior wall targets are exposed by placing the cardiac positioner onto the acute margin of the heart and pulling it towards the patient's left shoulder, followed by insertion of the epicardial stabilizer to surround the target vessel (Figure 4). Lateral wall targets involve placing the cardiac positioner along the axis of the target coronary artery, $\sim 3 \mathrm{~cm}$ distal from the anastomotic site, and pulling it toward the patient's right hip, followed by placement of the epicardial stabilizer. Careful attention to measuring graft length and ensuring adequate conduit orientation is germane; conduits should be marked on their anterior surface and length determinations should involve gentle stretching of the conduit to the anastomotic site, plus the addition of $\sim 2 \mathrm{~cm}(\sim 3-4 \mathrm{~cm}$ if the patient is supported on cardiopulmonary bypass). A knot pusher should not be required to tie distal anastomotic sutures. Other technical points include not starting the anastomosis until excellent exposure of the target vessel has been achieved, and not hesitating to use femorofemoral cardiopulmonary bypass (CPB) support to facilitate grafting of inferior and lateral wall vessels. In this regard, peripheral CPB use (without cardioplegic arrest) leads to a smaller cardiac 


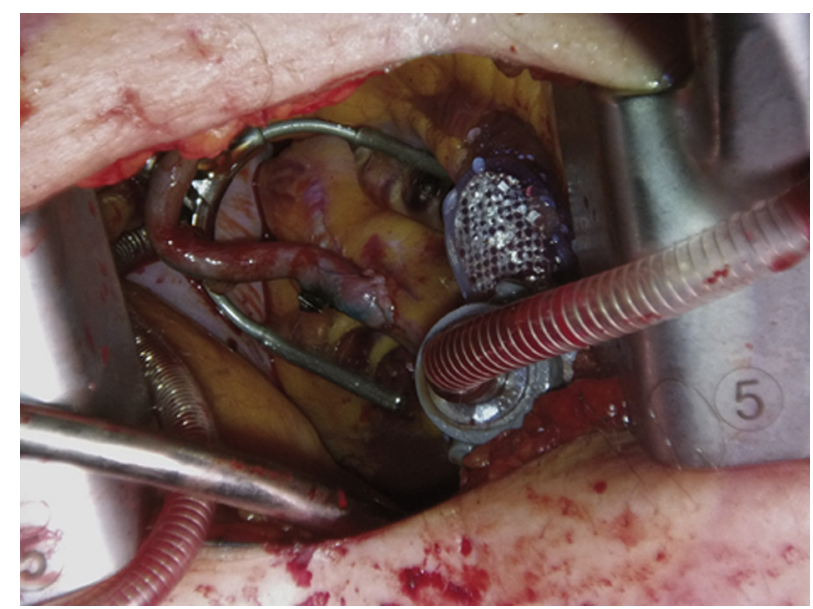

FIGURE 4. MICS CABG distal anastomoses. Through a $5-\mathrm{cm}$ thoracotomy incision, the posterior descending branch of the right coronary artery was exposed and a graft was handsewn to it. The lateral and anterior left ventricular walls (not shown) can readily be exposed in a similar fashion.

size, more working space within the chest, hemodynamic stability, greater ease of mobilizing the heart within the small thoracotomy incision and -in our experience- no additional complications. ${ }^{4}$ All completed grafts must be quality-checked by transit time flow measurements. ${ }^{16}$ After completion of all anastomoses, the position and lie of each graft is visually confirmed once both lungs have been re-expanded.

\section{WHAT IS KNOWN ABOUT MICS CABG AND WHAT REMAINS TO BE DEMONSTRATED}

MICS CABG has been shown to be safe and feasible at several expert centers, with high patient satisfaction (Figure 5). ${ }^{2,3,14,17-20}$ In the consecutive experience of 510 MICS CABG patients at the University of Ottawa Heart Institute, operated at median age of 64.0 years (interquartile range, 57.0-71.0 years), conversion to sternotomy occurred in 20 patients $(3.9 \%), 79(15.6 \%)$ required CPB support and, apart from 34 patients $(6.7 \%)$ who underwent a planned hybrid coronary revascularization, complete territory-based revascularization was achieved in all patients. ${ }^{21}$ Perioperative mortality and stroke each occurred in 1 patient, for an incidence of $0.2 \%{ }^{6}$

The 3 key questions that remain regarding the role of MICS CABG toward making surgical coronary revascularization less invasive are: Is MICS CABG durable? Is MICS CABG truly less invasive than CABG via sternotomy? Is MICS CABG teachable and widely diffusible?

The first of these questions was recently addressed by a complete late follow-up analysis of the Ottawa series $(\mathrm{N}=510)$ published in the Journal of the American College of Cardiology. In this report, the results of MICS CABG showed high durability at 10 years, with more than $90 \%$ of patients alive and $80 \%$ of patients both alive and free from any major adverse cardiovascular or cerebrovascular event, including repeat revascularisation. ${ }^{6}$

The second key question is being evaluated in the Minimally Invasive versus STernotomy (MIST) clinical trial,

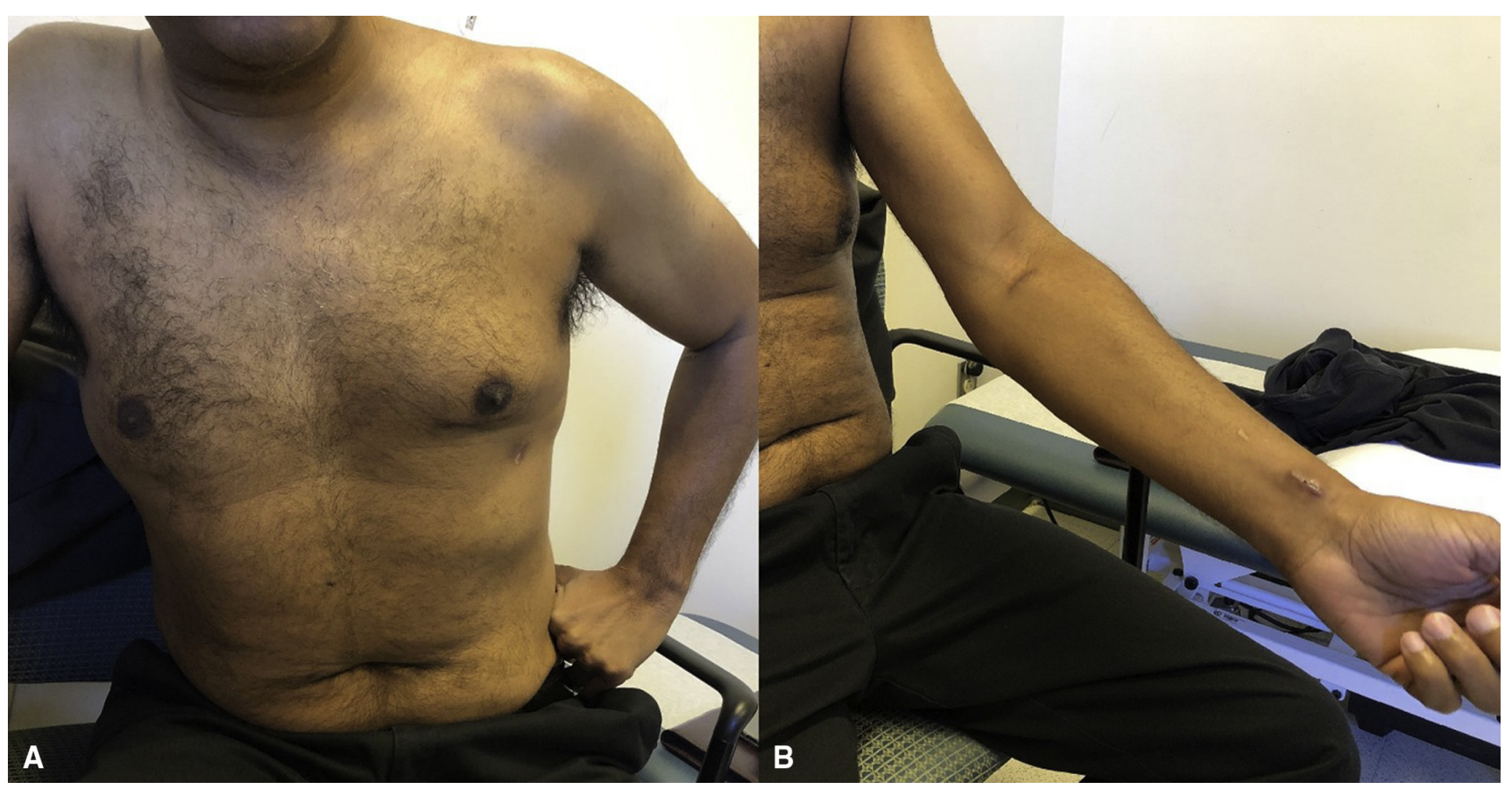

FIGURE 5. MICS CABG incisions 1 month postoperatively. Patient who underwent (A) multiarterial multivessel MICS CABG with (B) an endoscopically harvested left radial artery. Consent to the use of the photos was provided by the patient. 
which is nearly halfway through its recruitment of 166 patients. The trial randomizes patients to undergo multivessel MICS CABG versus CABG by sternotomy and has a primary end point of patient-reported quality of life measures, assessed by the short-form 36 questionnaire at 4 weeks postoperatively. ${ }^{7}$ The MIST trial may also be the first to address, in a randomized controlled setting, the controversial issue of comparative invasiveness between sternotomy and nonsternotomy cardiac surgery approaches.

The third key question, which pertains to the wider applicability of MICS CABG, may take many years to answer. OPCAB, a much less technically demanding operation than MICS CABG, has received only limited adoption over the years. While the wariness toward OPCAB may relate in part to its greater technical requirements compared with on-pump CABG, OPCAB also lacks clear advantages for the patient from an invasiveness standpoint. Now, with demonstrated durability, should MICS CABG also be effective at objectively reducing the intrusiveness of surgical coronary revascularization, it is foreseen that dedicated and sustained efforts at adopting MICS CABG would be undertaken by a growing number of centers.

\section{CONCLUSIONS}

Cardiac surgery needs to move forward and offer lessinvasive solutions to its patients. The most robust adult cardiac operation -ie, the one whose results are most incrementally superior to that of catheter-based or medical alternatives-is CABG. ${ }^{22}$ However, we surgeons cannot anticipate that our trainees will continue to routinely be performing CABG 20 years from now by cutting the sternum open with a saw and putting ice on the arrested heart. Our patients, who increasingly are elderly and have limited osteogenic and wound healing ability, do suffer from the invasiveness of sternotomy, which we collectively must address or face that the otherwise-beneficial CABG operation will disappear. The candidate $\mathrm{CABG}$ operation of the future should be safe, effective, and durable while less invasive and widely applicable, without requiring major investments such as the purchase of a surgical robot. MICS CABG could represent such an operation but currently remains difficult to perform by nonexperts and insufficiently widespread in adoption. We must aspire, with continuing research and a strong sense of surgical mentorship and mutual support, that we will one day be able to offer to most patients in need of a CABG operation one that will safely, effectively and routinely meet their needs without the major invasion of a sternotomy.

\section{Conflict of Interest Statement}

Dr Ruel is a minimally invasive coronary artery bypass grafting.proctor and principal investigator of the Minimally Invasive versus STernotomy (MIST) trial (both with support from Medtronic, Inc).
The Journal policy requires editors and reviewers to disclose conflicts of interest and to decline handling or reviewing manuscripts for which they may have a conflict of interest. The editors and reviewers of this article have no conflicts of interest.

\section{References}

1. Kolesov VI, Potashov LV. Surgery of coronary arteries. Eksp Khir Anesteziol. 1965;10:3-8 [in Russian].

2. McGinn JT Jr, Usman S, Lapierre H, Pothula VR, Mesana TG, Ruel M. Minimally invasive coronary artery bypass grafting: dual-center experience in 450 consecutive patients. Circulation. 2009;120:S78-84.

3. Lapierre H, Chan V, Sohmer B, Mesana TG, Ruel M. Minimally invasive coronary artery bypass grafting via a small thoracotomy versus off-pump: a casematched study. Eur J Cardiothorac Surg. 2011;40:804-10.

4. Une D, Lapierre H, Sohmer B, Rai V, Ruel M. Can minimally invasive coronary artery bypass grafting be initiated and practiced safely? A learning curve analysis. Innovations (Phila). 2013;8:403-9.

5. Ruel M, Shariff MA, Lapierre H, Goyal N, Dennie C, Sadel SM, et al. Results of the minimally invasive coronary artery bypass grafting angiographic patency study. J Thorac Cardiovasc Surg. 2014; 147:203-8.

6. Guo MH, Vo TX, Horsthuis K, Rahmouni K, Chong AY, Glineur D, et al. Durability of minimally invasive coronary artery bypass grafting: 10-year outcomes in 510 consecutive patients. J Am Coll Cardiol. 2021;78:1390-1.

7. Guo MH, Wells GA, Glineur D, Fortier J, Davierwala PM, Kikuchi K, et al. Minimally Invasive coronary surgery compared to STernotomy coronary artery bypass grafting: the MIST trial. Contemp Clin Trials. 2019; $78: 140-5$.

8. Meyerson J, Thelin S, Gordh T, Karlsten R. The incidence of chronic poststernotomy pain after cardiac surgery - a prospective study. Acta Anaesthesiol Scand. 2001;45:940-4.

9. Abdallah MS, Wang K, Magnuson EA, Spertus JA, Farkouh ME, Fuster V, et al Quality of life after PCI vs CABG among patients with diabetes and multivessel coronary artery disease: a randomized clinical trial. JAMA. 2013;310: 1581-90.

10. Wang B, He D, Wang M, Qian Y, Lu Y, Shi X, et al. Analysis of sternal healing after median sternotomy in low risk patients at midterm follow-up: retrospective cohort study from two centres. J Cardiothorac Surg. 2019;14: 193.

11. Kulik A. Quality of life after coronary artery bypass graft surgery versus percutaneous coronary intervention: what do the trials tell us? Curr Opin Cardiol. 2017;32:707-14.

12. Abdallah MS, Wang K, Magnuson EA, Osnabrugge RL, Kappetein AP, Morice MC, et al; SYNTAX Trial Investigators. Quality of life after surgery or DES in patients with 3-vessel or left main disease. J Am Coll Cardiol. 2017; 69:2039-50.

13. Kikuchi K, Une D, Kurata A, Ruel M. Off-pump minimally invasive coronary artery bypass grafting using the bilateral internal thoracic arteries and the right gastroepiproic artery. Eur J Cardiothorac Surg. 2016;49:1285-6.

14. Davierwala PM, Verevkin A, Sgouropoulou S, Hasheminejad E, von Aspern K, Misfeld M, et al. Minimally invasive coronary bypass surgery with bilateral internal thoracic arteries: early outcomes and angiographic patency. J Thorac Cardiovasc Surg. 2021;162:1109-19.e4.

15. Chan V, Lapierre H, Sohmer B, Mesana TG, Ruel M. Handsewn proximal anas tomoses onto the ascending aorta through a small left thoracotomy during minimally invasive multivessel coronary artery bypass grafting: a stepwise approach to safety and reproducibility. Semin Thorac Cardiovasc Surg. 2012; 24:79-83.

16. Gaudino M, Sandner S, Di Giammarco G, Di Franco A, Arai H, Asai T, et al. The use of intraoperative transit time flow measurement for coronary artery bypass surgery: systematic review of the evidence and expert opinion statements. Circulation. 2021;144:1160-71.

17. Nambiar P, Kumar S, Mittal CM, Sarkar IC. Outcomes of bilateral internal thoracic arteries in minimally invasive coronary artery bypass grafting with analogy to the SYNTAX trial. Innovations (Phila). 2019;14:227-35.

18. Rajput NK, Kalangi TKV, Andappan A, Swain AK. MICS CABG: a singlecenter experience of the first 100 cases. Indian J Thorac Cardiovasc Surg. 2021;37:16-26.

19. Teman NR, Hawkins RB, Charles EJ, Mehaffey JH, Speir AM, Quader MA, et al; Investigators for the Virginia Cardiac Services Quality Initiative. Minimally 
invasive vs open coronary surgery: a multi-institutional analysis of cost and outcomes. Ann Thorac Surg. 2021;111:1478-84.

20. Rabindranauth P, Burns JG, Vessey TT, Mathiason MA, Kallies KJ, Paramesh V. Minimally invasive coronary artery bypass grafting is associated with improved clinical outcomes. Innovations (Phila). 2014;9:421-6.

21. Vo TX, Glineur D, Ruel M. Commentary: complete revascularization in coronary artery bypass grafting-sometimes it pays to be conservative. J Thorac Cardiovasc Surg. July 6, 2021 [Epub ahead of print].
22. Ruel M, Falk V, Farkouh ME, Freemantle N, Gaudino MF, Glineur D, et al Myocardial revascularization trials. Circulation. 2018;138:2943-51.

Key Words: coronary artery bypass grafting, coronary artery disease, long-term outcomes, minimally invasive cardiac surgery, observational studies, randomized controlled trials 